\title{
Filtration of nanoparticles: Evolution of cake structure and pressure-drop
}

\author{
Tobias D. Elmøe ${ }^{\mathrm{a}}$, Antonio Tricoli ${ }^{\mathrm{a}}$, Jan-Dierk Grunwaldt ${ }^{\mathrm{b}}$, Sotiris E. Pratsinis ${ }^{\mathrm{a}, *}$ \\ ${ }^{a}$ Particle Technology Laboratory, Department of Mechanical and Process Engineering, Sonneggstrasse 3, ML F13, ETH Zurich, CH-8092 Zurich, Switzerland \\ ${ }^{\mathrm{b}}$ Department of Chemical and Biochemical Engineering, Technical University of Denmark, DK-2800 Lyngby, Denmark
}

\section{A R T I C L E I N F O}

\section{Article history:}

Received 6 April 2009

Received in revised form

16 July 2009

Accepted 3 September 2009

\section{Keywords:}

Filtration

Cake morphology

Deposit morphology

Langevin dynamics

Clogging

Pressure-drop

Nanoparticles

\begin{abstract}
A B S T R A C T
The detailed three-dimensional accumulation of deposits and the build-up of pressuredrop during filtration of compressible gases laden with nanoparticles (diameter $d_{p}=50 \mathrm{~nm}$ ) through capillaries (1-4 $\mu$ m radius) was investigated by Langevin dynamics (LD) at Peclet number, $P e, 0.01-10$. At low $P e$, highly porous (98\%) deposits were formed while at higher Pe the porosity was slightly reduced including a void cone upstream of the capillary inlet. Three distinct deposition regimes were identified: capillary deposition, clogging and cake growth. At the time of clogging $\left(t_{c l}\right)$, a filter cake with constant solid volume fraction began to form, accompanied with build-up of pressuredrop which was in excellent agreement with classic cake filtration theory. An expression for the solid volume fraction of the cake $\left(\phi_{s d, c}\right)$ was obtained as a sole function of $P e$. In addition, the filtration efficiency became 1 after clogging, since the cake acts as a perfectly efficient filter. Penetration of nanoparticles takes place until the onset of cake filtration at high $P e(1-10)$ while for smaller ones $(0.01-0.1)$ it is negligible at the employed capillary radii and length $(10 \mu \mathrm{m})$. Analytical expressions for the time of capillary clogging and height of the void cone were derived and were in agreement to LD simulations. The height of the void cone is in the order of one capillary diameter at high Pe.
\end{abstract}

(c) 2009 Elsevier Ltd. All rights reserved.

\section{Introduction}

Filtering a nanoparticle-laden gas through a porous substrate results in a homogeneous and highly porous film (Andersen et al., 2002). In filtration the physical properties of that film are determined by the Peclet number (Pe), the ratio of convective to diffusive transport (Przekop, Moskal, \& Gradon, 2003). Porous ceramic films have applications as membrane filters (Andersen et al., 2002), in catalysis (Thybo et al., 2004), fuel cells (Chakraborty, Bischoff, Chorkendorff, \& Johannessen, 2005), and gas sensors (Mädler, \& Roessler et al., 2006).

While understanding the influence of deposition conditions on the morphology of films deposited on flat non-porous surfaces has been investigated broadly (Mädler, Lall, \& Friedlander, 2006; Veerapaneni \& Wiesner, 1994), only few have addressed the deposition on porous (filter) materials: Schmidt (1996) first studied deposition of large particles $(2-6 \mu \mathrm{m})$ during filtration in the ballistic regime $(P e>10)$ by Langevin dynamics without allowing for deposition inside the porous structure. Reis (2005) modeled the deposition of coke particles inside the porous structure of catalysts. Furthermore, nanoparticle deposition by filtration takes place at substantially lower Pe numbers (Wang, Chen, \& Pui, 2007).

\footnotetext{
* Corresponding author. Tel.: +4144632 3180 .

E-mail address: pratsinis@ptl.mavt.ethz.ch (S.E. Pratsinis).
} 


\begin{tabular}{|c|c|c|c|}
\hline \multicolumn{2}{|c|}{ Nomenclature } & \multirow{2}{*}{$\begin{array}{l}R_{e} \\
R_{o}\end{array}$} & \multirow{2}{*}{$\begin{array}{l}\text { effective rim radius }(\mathrm{m}) \\
\text { equivalent radius of circular particle-free re- } \\
\text { gion }(\mathrm{m})\end{array}$} \\
\hline$B_{0}$ & darcy permeability $\left(\mathrm{m}^{2}\right)$ & & \\
\hline$C_{n}$ & standard concentration of particles $\left(10^{14} \# / \mathrm{m}^{3}\right)$ & $t$ & time $(\mathrm{s})$ \\
\hline$C_{c}$ & Cunningham correction factor (dimensionless) & $t_{c l}$ & clogging time $(\mathrm{s})$ \\
\hline$d_{p}$ & particle size $(\mathrm{m})$ & $T$ & temperature (K) \\
\hline$D$ & particle diffusion coefficient $\left(\mathrm{m}^{2} / \mathrm{s}\right)$ & $U$ & fluid velocity inside and outside capillary $(\mathrm{m} / \mathrm{s})$ \\
\hline $\begin{array}{l}D_{e c} \\
F_{c i}\end{array}$ & $\begin{array}{l}\text { equivalent capillary size of deposit }(\mathrm{m}) \\
\text { fraction of particles entering capillary-inlet }\end{array}$ & $V_{p}(z)$ & $\begin{array}{l}\text { particle volume within a slice of thickness } d_{p} \\
\text { and at height } z\left(\mathrm{~m}^{3}\right)\end{array}$ \\
\hline & (dimensionless) & $X$ & Fraction of the total flux of particles contained \\
\hline$h_{c l}$ & clogging height $(\mathrm{m})$ & & between $R_{e}$ and $R_{e}-0.5 d_{p}$ \\
\hline$k_{1}, k_{2}$ & $\begin{array}{l}\text { structural constant groups of deposit formed } \\
\text { until } t_{c l}\left(\mathrm{~Pa}^{2}\right)\end{array}$ & $\begin{array}{l}z \\
z_{i}\end{array}$ & $\begin{array}{l}\text { depth (m) } \\
\text { height of growing clogging deposit (m) }\end{array}$ \\
\hline$\dot{n}$ & molar flow of gas $(\mathrm{mol} / \mathrm{s})$ & $\delta_{\text {cake }}$ & height of deposition domain (m) \\
\hline$\dot{N}_{c, i}$ & $\begin{array}{l}\text { flow of particles entering through capillary- } \\
\text { inlet }(\# / s)\end{array}$ & $\begin{array}{l}\delta_{\text {capillary }} \\
\delta_{c l}\end{array}$ & $\begin{array}{l}\text { length of capillary }(\mathrm{m}) \\
\text { height of void-cone at time of clogging (m) }\end{array}$ \\
\hline$\dot{N}_{c, o}$ & $\begin{array}{l}\text { flow of particles exiting through the capillary- } \\
\text { outlet }(\# / s)\end{array}$ & $\begin{array}{l}\delta_{\text {drop }} \\
\Delta P\end{array}$ & $\begin{array}{l}\text { height of drop domain }(\mathrm{m}) \\
\text { pressure-drop across filter including deposit }\end{array}$ \\
\hline$\dot{N}_{i d}$ & flux of particles entering model domain (\#/s) & & \\
\hline$P$ & pressure $(\mathrm{Pa})$ & $\Delta P\left(t_{c l}\right)$ & pressure-drop at the onset of clogging (Pa) \\
\hline $\bar{P}$ & $\begin{array}{l}\text { overall penetration through filter (dimension- } \\
\text { less) }\end{array}$ & $\begin{array}{l}\Delta P_{\text {cake }} \\
\Delta P_{c l}\end{array}$ & $\begin{array}{l}\text { pressure-drop through filtration cake }(\mathrm{Pa}) \\
\text { pressure-drop through clogging deposit }(\mathrm{Pa})\end{array}$ \\
\hline$P_{0}$ & inlet pressure $(101,325 \mathrm{~Pa})$ & $\Delta t$ & time step used in integration $(\mathrm{s})$ \\
\hline$P_{c, i}$ & pressure at capillary inlet $\operatorname{rim}(\mathrm{Pa})$ & $\eta$ & filtration efficiency (dimensionless) \\
\hline $\begin{array}{l}P_{c, o} \\
P_{i}\end{array}$ & $\begin{array}{l}\text { pressure at capillary outlet }(\mathrm{Pa}) \\
\text { pressure at clog-cake interface }(\mathrm{Pa})\end{array}$ & $\kappa$ & $\begin{array}{l}\text { structural parameter of deposit formed until } t_{c l} \\
\left(\mathrm{~Pa}^{2}\right)\end{array}$ \\
\hline $\mathrm{Pe}$ & Peclet number $\left(d_{p} U / 2 \mathrm{D}\right)$ & $\mu$ & viscosity of gas $(\mathrm{kg} / \mathrm{ms})$ \\
\hline$Q$ & flow through capillary at pressure $P\left(\mathrm{~m}^{3} / \mathrm{s}\right)$ & $\rho_{1}$ & standard density of particles $\left(1000 \mathrm{~kg} / \mathrm{m}^{3}\right)$ \\
\hline$Q_{0}$ & flow through capillary at $P=P_{0}\left(\mathrm{~m}^{3} / \mathrm{s}\right)$ & $\tau$ & tortuosity (dimensionless) \\
\hline$R$ & gas constant $(8.3145 \mathrm{~J} / \mathrm{mol} \mathrm{K})$ & $\tau_{w}$ & maximum shear stress at capillary wall $(\mathrm{Pa})$ \\
\hline$R_{c}$ & capillary radius $(\mathrm{m})$ & $\phi_{s d}$ & solid volume fraction (dimensionless) \\
\hline$R_{c, e}$ & effective capillary radius $(\mathrm{m})$ & $\phi_{s d, c}$ & cake solid volume fraction (dimensionless) \\
\hline
\end{tabular}

An important filtration parameter is the pressure-drop evolution (Calle, Contal, Thomas, Bemer, \& Leclerc, 2002a; Stenhouse \& Trottier, 1991). Three regimes have been identified experimentally (Japuntich, Stenhouse, \& Liu, 1994): In the first, particles deposit within the filter and the pressure-drop slightly increases with mass-loading. In the second, the captured particles start collecting incoming particles and clogging commences increasing further the pressuredrop. In the third regime, the filter cake is formed and the pressure-drop increases rapidly. Several models have been set to describe especially the third regime (Calle, Contal, Thomas, Bemer, \& Leclerc, 2002b; Novick, Monson, \& Ellison, 1992). In most, an assumption of the deposit geometry is required. Only few models actually cover all 3 regimes (Kirsch, 1998; Thomas, Penicot, Contal, Leclerc, \& Vendel, 2001) requiring, however, an assumption for the onset of cake formation.

Another important parameter is the fraction of particles penetrating the filter which in turn yields the filtration efficiency. Podgórski (2009) estimated the penetration of nanoparticles through inhomogeneous fibrous filters neglecting flow obstruction and increased collection by deposited particles, assuming the so-called perfect sink conditions. Therefore only the upper limit of penetration was studied that changes, however, with time as it has been shown experimentally (Calle et al., 2002a; Hinds \& Kadrichu, 1997).

Here, the complete evolution of cake structure and pressure-drop from particle deposition inside a capillary to cake growth outside that capillary is obtained by Langevin dynamics (Ermak \& Buckholz, 1980; Heine \& Pratsinis, 2007) during nanoparticle filtration for a wide range of Pe numbers (0.01-10) without any assumption on cake formation time. In fact, here the onset of cake formation is calculated from first principles. From the detailed evolution of the deposit morphology, the pressure-drop build-up in a highly porous filter is obtained, accounting for all three filtration regimes. That way the detailed structure of such deposits is revealed and, most importantly, the fraction of particles penetrating through a capillary is calculated. The model is validated in the limits of purely diffusional deposition $(P e \rightarrow 0)$ and purely ballistic deposition $(P e \rightarrow \infty)$, as well as against filtration theory. 


\section{Theory}

\subsection{Model overview}

The structure of a porous substrate can be approximated as parallel cylindrical capillaries as in nuclepore filters (Spurny, Lodge, Frank, \& Sheesley, 1969). Here, this structure was chosen, as it allows studying the transition from capillary deposition to cake growth. The assumption applies best to highly porous filters (porosity $>90 \%$ ) where the outside surface makes up a negligible fraction of the total filter area. Even for less porous filters (down to 10\% porosity), several studies have shown the initial deposition on the outside filter surface to be small. Smith and Phillips (1975) studied the flow to a capillary in a nuclepore filter with $10 \%$ porosity, at a fluid velocity of $1 \mathrm{~m} / \mathrm{s}$, and a Reynolds number, Re=1. They found a stagnant zone with no recirculation at the filter surface where deposition by impaction and interception was low (Stokes number, $S t=0-5$ ). Manton (1978) solved the flow-field equations analytically in the limit of $R e=0$ and found good agreement with Smith and Phillips (1975). Both studies agree well with Spurny et al. (1969) and Fan and Gentry (1978) who observed particle deposition initially to occur mainly around the inlet rim of nuclepore filter capillaries.

Here for $P e=0.01-10$, the $S t$ and Re numbers are comparable to the above studies $\left(S t \approx 2 \times 10^{-6}-2 \times 10^{-3}\right.$, and $R e \approx 2 \times 10^{-4}-0.2$ ) so the deposition at the filter surface is expected to be small and negligible with the given porosity and flow (down to 90\%/stagnant zone). Fig. 1 shows the model domain. Monodisperse particles deposit one at a time (Tassopoulos, Obrien, \& Rosner, 1989) as they flow through a capillary. In order to obtain true random motion before deposition, the particle is released at a certain distance from the capillary-inlet (Fig. 1: drop domain). The detailed movement of a particle is determined by the solution of the Langevin equation. The time-step $(\Delta t)$ used in the integration of the Langevin equation, is chosen so that the value of the root mean square displacement by particle diffusion is equal to $50 \%$ of the particle diameter (Heine \& Pratsinis, 2007). If the time-step is large and the fluid velocity is high, the time-step is calculated from the average fluid velocity instead, allowing for a maximum displacement of $50 \%$ of the particle diameter in the axial direction. This was validated by calculating the particle diffusivity, which has less than $5 \%$ difference from the Einstein-equation including slip-correction (Friedlander, 2000).

Particles only deposit by touching and sticking to the capillary wall or other immobilized particles. A sticking coefficient of $100 \%$ is assumed (Mädler, \& Lall et al., 2006; Rodríguez-Pérez, Castillo, \& Antoranz, 2005) that applies best for particle diameters between $10 \mathrm{~nm}$ (Wang \& Kasper, 1991) and $5 \mu \mathrm{m}$ (Pawu \& Braaten, 1995). Tricoli et al. (2008) measured the adhesion strength of thermophoretically-deposited nanoparticle layers $\left(d_{p}=10 \mathrm{~nm}\right)$ by gas impingement. They showed that an area with equivalent diameter of $1.04 \mathrm{~cm}$ could be removed by impinging a $\mathrm{N}_{2}$ jet with a flow velocity of approximately $236 \mathrm{~m} / \mathrm{s}$. This translates into a minimum shear stress for resuspension, $\tau_{w}=101 \mathrm{~Pa}$ (Russ \& Talbot, 1998). This is considerably higher than the maximum shear stress obtained here near the capillary wall (Bird, Stewart, \& Lightfoot, 2002) $\left(\tau_{w}=60-14\right.$ Pa

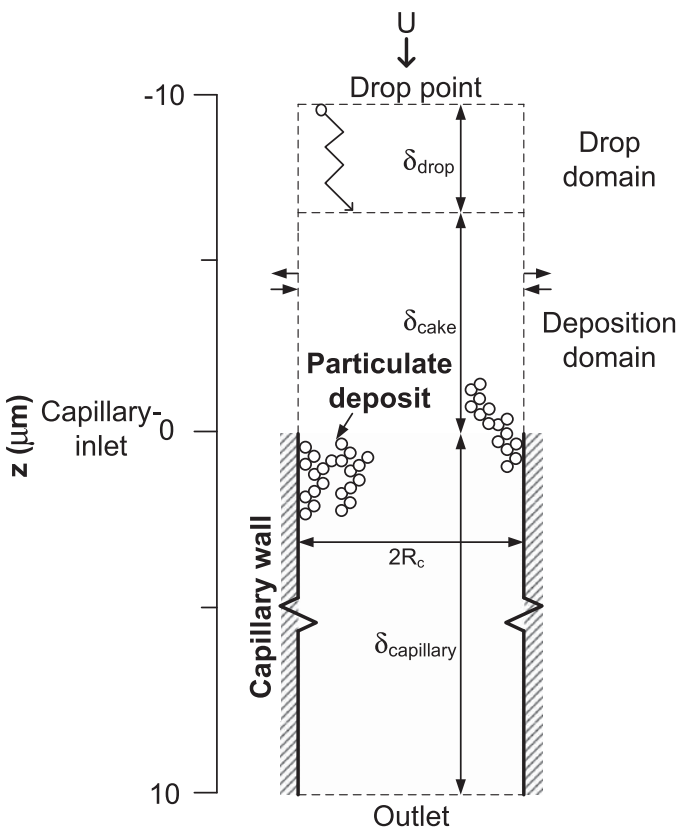

Fig. 1. Schematic of the simulated domain and boundary conditions of nanoparticle filtration through a single capillary. Particles are inserted at the top (drop point) and flow downstream. First through the drop domain $\left(\delta_{\text {drop }}\right)$ where deposition is not allowed in order to assure true random motion. They continue in the deposition domain where they deposit by colliding either with previously deposited particles or the capillary walls. If a particle reaches the outlet without collision it exits the domain and a new particle is inserted at the top. 
for $R_{C}=1-4 \mu \mathrm{m}$ at $P e=10$ ). Therefore, no restructuring or resuspension is expected at the employed capillary radii and $P e$ numbers.

If a particle escapes the domain on its way to the capillary, it is reintroduced with an opposite velocity vector: open boundary (Heine \& Pratsinis, 2007). Particles that penetrate through the capillary (e.g. reach its outlet without depositing) are counted and a new particle is inserted at the inlet. To compare with past works on particle deposition, the flow-field is assumed to be plug-flow and the fluid velocity to be constant in time, as the solid volume fraction of the deposits is expected to be low (Mädler, \& Lall et al., 2006; Schmidt, 1996). The deposits were characterized by their solid volume fraction. The filtration dynamics were elucidated by calculating the clogging time $\left(t_{c l}\right)$, filtration efficiency $(\eta)$ and pressuredrop evolution $(\Delta P(t))$.

\subsubsection{Characterization}

The solid volume fraction of the deposit $\left(\phi_{s d}\right)$ in a given deposition domain slice of thickness $d_{p}$ (one particle diameter), is found by calculating the ratio of particle volume within that slice to the total volume $\left(\pi R_{c}^{2} d_{p}\right)$ of the slice (RodríguezPérez et al., 2005):

$$
\phi_{s d}=\frac{V_{p}(z)}{\pi R_{c}^{2} d_{p}}
$$

where $V_{p}(z)$ is the volume occupied by particles in the slice at height $z$ and thickness $d_{p}$.

Initially, particle deposition takes place inside the capillary then proceeds to form a cake outside of the capillary. The onset of cake formation is characterized by the clogging time, $t_{c l}$. The fraction of the total particle flux entering the capillary-inlet is:

$$
F_{c, i}=\frac{\dot{N}_{c, i}}{\dot{N}_{i d}}
$$

where $\dot{N}_{c, i}$ is the flow of particles (\#/s) at the inlet of the capillary and $\dot{N}_{i d}$ is the flow of particles entering the deposition domain (Fig. 1). The $t_{c l}$ is defined as the time required until $F_{c, i}$ is lower than $0.1 \%$.

The filtration efficiency, $\eta$, is the fraction of total particle flux collected by capillary and cake:

$$
\eta=1-\frac{\dot{N}_{c, o}}{\dot{N}_{i d}}
$$

where $\dot{N}_{c, o}$ is the flow of particles exiting the substrate capillary. As particle penetration changes with time, another important parameter is the overall penetration: the accumulated fraction of the total number of particles that have penetrated during filtration for time $t$ :

$$
\bar{P}=\int_{t=0}^{t}\left(1-\eta\left(t^{\prime}\right)\right) d t^{\prime}
$$

\subsection{Simplified model for clogging time and void-cone height}

During filtration at high Pe numbers, where particle motion is mainly ballistic, particles initially deposit by interception at the capillary rim narrowing (shading) it. This "shading" leads to pile up of particles on top of the deposited (or intercepted) ones causing a particle build-up there. The continued interception near the rim of the shaded region causes further narrowing of the rim itself. This continues until complete closing of the capillary, the so-called capillary clogging. If $R_{e}$ is the effective rim radius, then a mass-balance near the rim may be set-up to estimate the time for clogging, as well as the deposit height at clogging:

$$
\underbrace{\pi\left(R_{e}(t)^{2}-R_{e}(t+\Delta t)^{2}\right) \cdot d_{p} \cdot \phi_{s d, c l}}_{\text {Volume change }}=\underbrace{X \cdot Q_{0} C_{n} v_{p} \Delta t}_{\text {Deposited volume }}
$$

where $\phi_{s d, c l}$ is the solid volume fraction of the clog which is assumed constant and isotropic, $v_{p}$ is the volume of a single particle and $X$ is the fraction of the total flux of particles that are flowing through $R_{e}$ and $R_{e}-0.5 d_{p}$, with the latter being the maximum distance at which a single particle can be collected (or intercepted). The assumption of constant and isotropic solid volume fraction was justified by LD calculations of the radial and axial solid volume fraction profile inside the deposit only. Close to the capillary inlet it was observed that $\phi_{s d, c l}$ did indeed converge to a constant value in both radial and axial direction. In fact, the $\phi_{s d, c l}$ was similar to the so-called cake solid volume fraction, $\phi_{s d, c}$, which is the constant $\phi_{s d}$ of a filter cake. Therefore, $\phi_{s d, c l}$ is replaced by $\phi_{s d, c}$ in Eq. (5). The value of $X$ is:

$$
X=\frac{C_{n} 2 \pi \Delta z \int_{R_{e}-0.5 d_{p}}^{R_{e}} r d r}{C_{n} 2 \pi \Delta z \int_{0}^{R_{c}} r d r}=\frac{R_{e} d_{p}}{R_{c}^{2}}-0.25\left(\frac{d_{p}}{R_{c}}\right)^{2} \simeq \frac{R_{e} d_{p}}{R_{c}^{2}}
$$

The second term in Eq. (6), $\left(0.25\left(d_{p} / R_{c}\right)^{2}\right)$, is a second order term of $d_{p} / R_{c}$ which by definition is a very small number. For example, it is equal to $1.56 \times 10^{-4}$ for particles of $d_{p}=50 \mathrm{~nm}$ with $R_{c}=2 \mu \mathrm{m}$. It only becomes important in comparison to the 
first term $\left(R_{e} d_{p} / R_{c}^{2}\right)$ when $R_{e}$ has become very small, near the clogging time. Nevertheless, it can be neglected without a large error ( $<5 \%$ ). Inserting Eq. (6) into (5), observing $U=Q_{0} / \pi R_{c}^{2}$ and letting $\Delta t \rightarrow 0$ gives:

$$
2 \frac{d R_{e}}{d t}=-\frac{U C_{n} v_{p}}{\phi_{s d, c}}
$$

As $R_{e}(t=0)=R_{c}$, the $t_{c l}$ is found by integrating Eq. (7) and setting $R_{e}=0$ :

$$
t_{c l}=\frac{2 R_{c} \phi_{s d, c}}{U C_{n} v_{p}}
$$

The $\phi_{s d, c}$ is a function of the Pe number as it will be shown later on (e.g. Fig. 7).

Eq. (8) was derived without any assumption of the clog geometry that would have made possible to estimate the clog height at the $t_{c l}$. Based on simulations here as it will be shown later on (e.g. Fig. 2), at large Pe, the clog structure resembles that of a void-cone. Therefore, a mass-balance may be set up on a differential volume of a void-cone:

$$
\underbrace{\pi\left(R_{c}^{2}-R_{e}^{2}\right) \Delta z \cdot \phi_{s d, c}}_{\text {Volume increase of cone }}=\underbrace{Q_{0} C_{n} v_{p} \overbrace{\left(1-\frac{R_{e}^{2}}{R_{c}^{2}}\right)}^{\text {Fraction intercepted }}}_{\text {Particles piled on top of cone }} \Delta t
$$

Rearranging Eq. (9), and letting $\Delta t \rightarrow 0$ gives a differential equation for the void-cone height:

$$
\frac{d z}{d t}=\frac{U C_{n} v_{p}}{\phi_{s d, c}}
$$

with initial condition $(t=0) z=0$. Integrating till $t=t_{c l}$, where $z=\delta_{c l}$, the cone height, yields:

$$
\delta_{c l}=\frac{U C_{n} v_{p}}{\phi_{s d, c}} t_{c l}
$$

Inserting Eq. (8) into (11) eliminates $t_{c l}$ and reduces the expression for $\delta_{c l}$ to:

$$
\delta_{c l}=2 R_{c}
$$

This shows that the height of the void-cone at high Pe should only depend on the filter capillary-size.

\subsection{Pressure-drop evolution}

Inside a capillary, the pressure-drop of a compressible gas is (Hagen-Poiseuille equation):

$$
Q(z)=-\frac{\pi R_{c, e}^{4}(t, z)}{8 \mu} \frac{d P(t)}{d z}
$$

where $d P(t) / d z$ is the pressure gradient, $\mu$ is the gas viscosity and $R_{c, e}(t, z)$ is the effective capillary radius that is related to $R_{c}$ by a mass-balance with the deposited particles inside the capillary:

$$
R_{c}^{2}\left(1-\phi_{s d}(t, z)\right)=R_{c, e}^{2}(t, z)
$$

This equation has been derived assuming a uniform particle coating in each slice $d z$ as in models for nuclepore filters (Fan \& Gentry, 1978; Spurny et al., 1969). Rewriting Eq. (13) in terms of the molar flow, $\dot{n}$, is more favorable, since $\dot{n}$ is independent on the depth as opposed to flowrate $Q$ which changes by compression:

$$
\frac{\dot{n} R T}{P}=-\frac{\pi\left(1-\phi_{s d}(t, z)\right)^{2} R_{c}^{4}}{8 \mu} \frac{d P}{d z}
$$

where $R$ is the gas constant $(8.3145 \mathrm{~J} / \mathrm{mol} \mathrm{K})$ and $T$ is the temperature. The flowrate at pressure $P_{0}$ is $Q_{0}=\left(\dot{n} R T / P_{0}\right)=U \pi R_{c}^{2}$ which is constant at the filter-face. So Eq. (15) is rewritten as:

$$
P \frac{d P}{d z}=-\frac{8 \mu U P_{0}}{\left(1-\phi_{s d}(t, z)\right)^{2} R_{c}^{2}}
$$

As the solid volume fraction profile, $\phi_{s d}(t, z)$, is known from LD computations, Eq. (16) can be solved numerically.

The pressure-drop through the deposit growing outside the capillary is modeled by a slightly modified version of Darcy's law, as that structure resembles more that of a porous film rather than that of a capillary. The molar flow through a slice $d z$ is (Jackson, 1977):

$$
\dot{n}=-\frac{\pi R_{c}^{2} B_{0}(t, z)}{\mu R T} P(t) \frac{d P(t)}{d z}
$$

where $B_{0}(t, z)$ is the permeability at time $t$ and depth $z$. Lundgren (1972) suggested replacing the viscosity with an effective one accounting for the solid volume fraction. The use of effective viscosity, however, is debated and may depend on the 
nature of the porous media as well (Nield \& Bejan, 2006). Here, in line with common practice within the field of filtration (Wakeman \& Tarleton, 1999), the fluid viscosity was used. Introducing $Q_{0}$, Eq. (17) becomes:

$$
P(t) \frac{d P(t)}{d z}=-\frac{\mu Q_{0} P_{0}}{\pi R_{c}^{2} B_{0}(t, z)}
$$

The $B_{0}(t, z)$ depends on the equivalent capillary-diameter of the deposit $\left(D_{e c}\right)$ and the tortuosity factor $\tau$ (Szekely, Evans, \& Sohn, 1976):

$$
B_{0}(t, z)=\frac{D_{e c}^{2}}{32}\left(\frac{1-\phi_{s d}}{\tau}\right)(t, z)
$$

At small $\phi_{s d}$, the $\tau$ approaches unity (Elias-Kohav, Sheintuch, \& Avnir, 1991). The deposit capillary size is expressed in terms of particle size and solid volume fraction (Ergun \& Orning, 1949):

$$
\frac{D_{e c}(t, z)}{d_{p}}=\frac{2}{3} \frac{1-\phi_{s d}(t, z)}{\phi_{s d}(t, z)}
$$

Inserting Eq. (20) in (19) gives the $B_{0}(t, z)$ in terms of $d_{p}$ and $\phi_{s d}$ :

$$
B_{0}(t, z)=\frac{d_{p}^{2}}{72} \frac{\left(1-\phi_{s d}(t, z)\right)^{3}}{\phi_{s d}(t, z)^{2}}
$$

The factor 1/72 in Eq. (21) is typically corrected by a factor of 2-2.5 in the denominator to match experimental data (Ergun \& Orning, 1949; Nakayama, Kuwahara, \& Sano, 2007). Here, the same correction factor, 2.08, is applied as for the widely used Ergun equation (Ergun \& Orning, 1949). Furthermore, slip flow around nanoparticles decreases the drag increasing the permeability (Novick et al., 1992; Song, Park, \& Lee, 2006) that becomes

$$
B_{0}(t, z)=\frac{C_{c} d_{p}^{2}}{150} \frac{\left(1-\phi_{s d}(t, z)\right)^{3}}{\phi_{s d}(t, z)^{2}}
$$

where $C_{c}$ is the Cunningham correction factor (Friedlander, 2000). From Eqs. (16) and (18) the total pressure-drop can be found numerically.

The present model accounts for end-effects, as pressure-drop depends on the average permeability that increases close to the end of the deposit since the solid volume fraction there decreases towards 0 . Typically, end-effects are not considered when calculating the pressure-drop evolution (Davies, 1970; Hinds \& Kadrichu, 1997; Kirsch, 1998; Spurny et al., 1969).

\subsection{Classic filtration theory}

After capillary clogging, a cake with constant $\phi_{s d}$ builds up according to classic theory of cake filtration (Ruth, 1935). For constant $\phi_{s d}$, the pressure-drop evolution through the filter cake is obtained analytically from Eq. (18) assuming $100 \%$ filtration efficiency:

$$
\Delta P_{\text {cake }}(t)=P_{0}-\sqrt{P_{0}^{2}-\frac{300 \mu U^{2} P_{0} \phi_{s d, c}}{C_{c} d_{p}^{2}\left(1-\phi_{s d, c}\right)^{3}} C_{n} v_{p}\left(t-t_{c l}\right)}, t>t_{c l}
$$

where $\phi_{s d, c}$ is the solid volume fraction of the cake and $t$ is the cake filtration time. Eq. (23) is rewritten for incompressible flows in terms of deposited mass per unit area (capillary section):

$$
\frac{\Delta P_{\text {cake }}}{U}=\frac{150 \mu \phi_{s d, c}}{C_{c} d_{p}^{2}\left(1-\phi_{s d, c}\right)^{3} \rho_{1}} \frac{m_{d}}{\pi R_{c}^{2}}
$$

where $m_{d}$ is the deposited mass. Eq. (24) shows that for incompressible gas flow normalizing the pressure-drop with the fluid velocity $U$, results in a linear relationship with the deposited mass per unit area $\left(m_{d} / \pi R_{c}^{2}\right)$. For deposits of the same $\phi_{s d, c}$, all such normalized pressure-drop evolutions should collapse onto a single line as observed also experimentally (Thomas et al., 2001). The total pressure-drop $\Delta P(t)$ is found by adding the pressure-drop through the structure deposited until the onset of clogging (initial deposit) to that of the cake, $\Delta P_{\text {cake }}(t)$. Assuming that this structure does not change after clogging, $\Delta P$ becomes (Appendix A):

$$
\Delta P(t)=P_{0}-\sqrt{\left(P_{0}-\Delta P_{\text {cake }}(t)\right)^{2}-2 \kappa}
$$

The constant $\kappa\left(\mathrm{Pa}^{2}\right)$ depends on the structure of the initial deposit:

$$
\kappa=\frac{1}{2}\left(P_{0}^{2}-\left(P_{0}-\Delta P\left(t_{c l}\right)\right)^{2}\right)
$$

where $\Delta P\left(t_{c l}\right)$ is the pressure-drop at $t_{c l}$. 
a
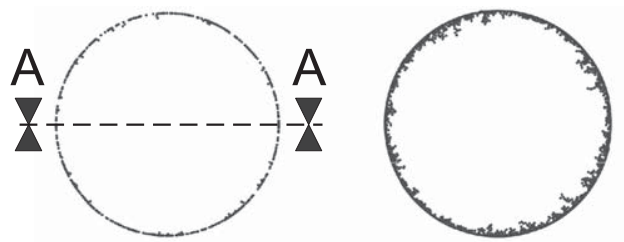

b
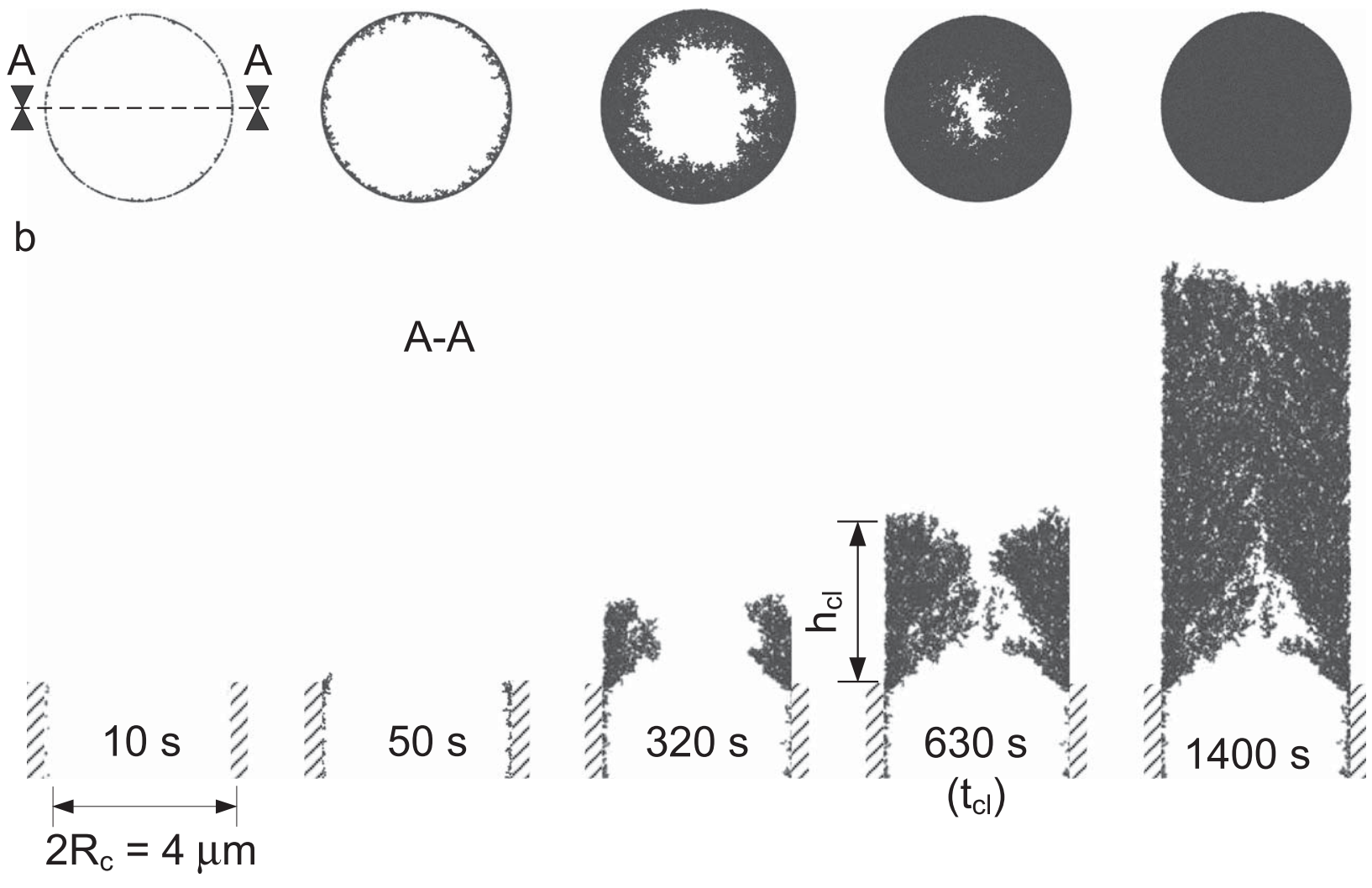

Fig. 2. Top view (a) and cross-sectional cut (b) of snapshots of particle deposits $\left(d_{p}=50 \mathrm{~nm}\right.$, number concentration: $\left.C_{n}=10^{14} \# / \mathrm{m}^{3}\right)$ at $P e=1$ and $R_{c}=2 \mu \mathrm{m}$ at $10,50,320,630$ and $1400 \mathrm{~s}$. Only the first $2 \mu \mathrm{m}$ of the $10 \mu \mathrm{m}$ long capillary is shown. The deposit grows outwards mainly from the capillary-inlet.

\section{Results and discussion}

\subsection{Deposition dynamics}

Simulations were carried out at the following conditions: $d_{p}=50 \mathrm{~nm}, R_{c}=1-4 \mu \mathrm{m}$, drop domain height $\delta_{d r o p}=1 \mu \mathrm{m}$, maximum cake thickness $\delta_{\text {cake }}=9 \mu \mathrm{m}$, capillary length $\delta_{\text {capillary }}=10 \mu \mathrm{m}$, particle concentration $C_{n}=10^{14} \# / \mathrm{m}^{3}$, solid density of particles $\rho_{1}=1000 \mathrm{~kg} / \mathrm{m}^{3}$, temperature $T=298 \mathrm{~K}$ and inlet pressure $P_{0}=1 \mathrm{~atm}$. Each simulation presented here is the average of 6 runs to account for the stochastic nature of Langevin dynamics. This was sufficient to get means with low standard deviation (e.g. 0.001-0.003 for $P e=0.01-10$ ).

Fig. 2 shows a top-down view (a) and a cross-sectional cut (b, marked on line A-A) of the developing structure above the substrate capillary for $R_{c}=2 \mu \mathrm{m}$ and $P e=1\left(d_{p}=50 \mathrm{~nm}, U_{0}=0.096 \mathrm{~m} / \mathrm{s}\right)$, which are typical conditions during filtration of nanoparticles (Wang et al., 2007). In the first $10 \mathrm{~s}$, particles flow through the capillary and deposit on its inner walls mostly by diffusion (Friedlander, 2000). At about $50 \mathrm{~s}$, however, particles start accumulating at its walls and most notably at its inlet rim capturing (intercepting) particles flowing to the capillary. This interception progressively narrows the rim and at $320 \mathrm{~s}$ the $R_{c}$ has been reduced by about $50 \%$ as deposited particles near the rim shade off the capillary (Fig. 2a).

As deposition continues (50-630 s), particles may either deposit on top or near the rim of the shaded area. The first leads to an increase in the height of the deposit while the latter results in a continuous increase of the shaded area (Fig. 2a). Both effects result in more and more particles being deposited at an increasing distance from the capillary inlet resulting in a void cone-like structure with increasing deposition time (Fig. 2b). At $630 \mathrm{~s}$ (b), the capillary is practically clogged as particles no longer penetrate through its inlet $\left(F_{c, i}=0\right)$. Further particle deposition (e.g. at $1400 \mathrm{~s}$ ) leads to cake growth upstream of the flow.

This agrees well with Spurny et al. (1969) who observed caps of particles building up above nuclepore filter capillaries. Also, Johannessen et al. (2004) showed that deposition of nanoparticles by filtration through a porous ceramic led to a homogeneous film on top of its surface with little particle penetration inside that porous structure. 

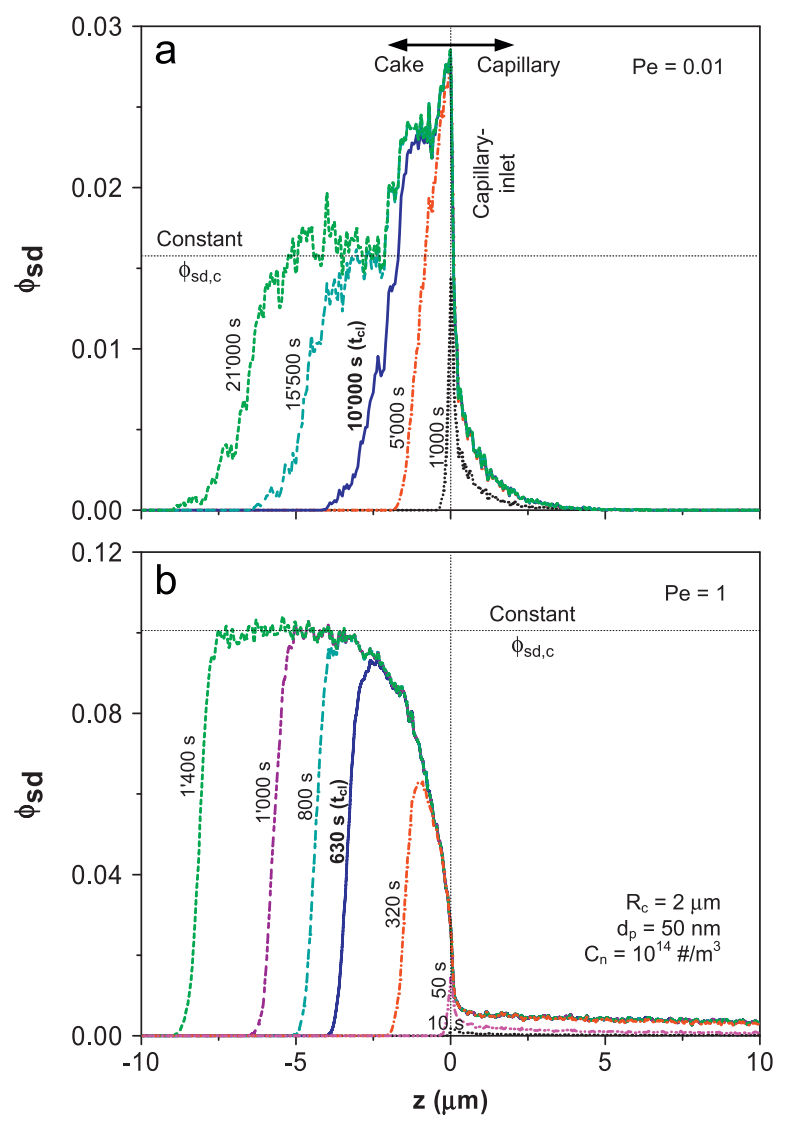

Fig. 3. Evolution of deposited solid volume fraction $\left(\phi_{s d}\right)$ profile for $P e=0.01$ (a) and 1 (b). In both cases deposition takes place initially mainly near the capillary-inlet. Subsequently, nearly all deposition occurs outside of the capillary. After clogging $\left(P e=0.01\right.$ and $1, t_{c l}=10,000$ and $630 \mathrm{~s}$ respectively), a constant solid volume fraction is reached.

Fig. 3 shows the evolution of the deposit solid volume fraction, $\phi_{s d}$, along the capillary axis corresponding to Fig. 2 for $P e=0.01$ (a) and 1 (b). Deposition starts near the capillary-inlet as shown in Fig. 2. For Pe=1 (Fig. 3b), at $10 \mathrm{~s}$ there is a small increase of $\phi_{s d}$ near the capillary-inlet from particles accumulating there. This increase around the rim continues at $t=50 \mathrm{~s}$, while the solid volume fraction inside the capillary only slightly increases. Later on ( $>320 \mathrm{~s}$, and up to $t_{c l}=630 \mathrm{~s}$ ), less and less deposition takes place inside the capillary as streamlines near the wall have been cleared from particles collected at the rim. As a result, flowing aerosol through the capillary has not enough time to diffusionally deposit on its walls. As the cake grows (50-630 s) upstream of the capillary, its $\phi_{s d}$ is increasing until it reaches a constant $\left(\phi_{s d, c}=0.10\right)$, which is also typical in flat surface deposition (Rodríguez-Pérez et al., 2005). Shortly after clogging ( $t_{c l}=630 \mathrm{~s}$ here), the $\phi_{s d, c}$ is attained throughout the growing cake ( $\phi_{s d, c}, t=800-1400 \mathrm{~s}$ ). Such cake structure is assumed in classic filtration theory (Ruth, 1935). These results indicate that this assumption is best after capillary clogging $\left(t>t_{c l}\right)$.

For $P e=0.01$ (Fig. 3a), the development of $\phi_{s d}$ is similar to $P e=1$, eventually leading to a constant $\phi_{s d}$ in the cake. However, for $P e=0.01$ the largest value of $\phi_{s d}$ is seen near the capillary inlet rather than in the cake itself. For deposition at low Pe, particles have no preferred direction, as the flow-field only plays a minor role. Therefore, also the effect of shading of the capillary inlet against the perpendicular convective flux, which was shown to be significant at $P e=1$ (cf. Fig. 2 ) to lead to formation of a void cone-like deposit, becomes smaller. The situation is similar to deposition on flat substrates, where a maximum $\phi_{s d}$ is observed for all Pe numbers near the substrate-deposit interface (Rodríguez-Pérez et al., 2005). Nevertheless, the $\phi_{s d}$ near the rim is similar for both $P e$, as it is dominated by the substrate (here rim). Away from the rim the $\phi_{s d}$ approaches its asymptotic cake values for ballistic $(P e \rightarrow \infty)$ and stochastic particle deposition $(P e \rightarrow 0)$.

Fig. 4 shows the particle fraction entering through the capillary-inlet, $F_{c, i}$, as a function of time for $R_{c}=2 \mu \mathrm{m}$. Three regimes are defined. First, capillary deposition up to $10 \mathrm{~s}$ for $P e=1$ : all particles enter through the capillary-inlet. Second, capillary clogging starts at $t>10 \mathrm{~s}$ and ends at about $630 \mathrm{~s}$ for $P e=1$ : deposition near the capillary-inlet starts decreasing the particle free area, which accelerates the deposition of particles outside of the capillary and the flux through the capillaryinlet decreases. Finally, cake growth $(t>630 \mathrm{~s})$ : no particles penetrate the capillary and a cake of constant solid volume fraction builds up as shown in Fig. 3. Fig. 4 shows that for decreasing Pe, fewer particles deposit per unit time prolonging the time it takes for deposit structures to develop. 


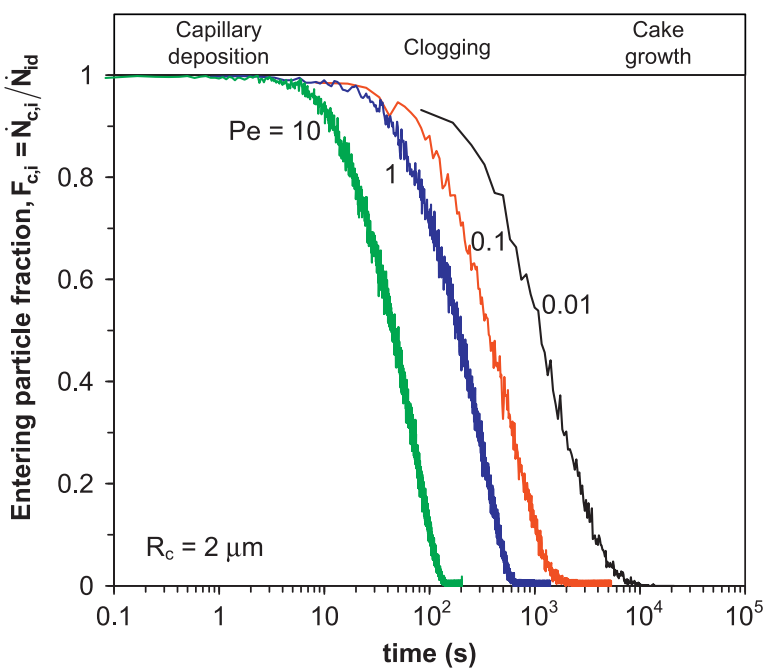

Fig. 4. Fraction $\left(F_{c, i}\right)$ of particles $\left(\dot{N}_{i d}\right)$ entering through capillary-inlet $\left(\dot{N}_{c, i}\right)$ for $P e=0.01-10$ as a function of time for $R_{c}=2 \mu \mathrm{m}$. Three regimes are observed: First, all particles penetrate through the capillary-inlet i.e. pure capillary deposition. Second, capillary becomes clogged and more and more particles deposit outside of the capillary. Third, capillary is totally clogged and no more particles can penetrate, leading only to cake growth.

\subsection{Cake morphology}

Fig. 5 shows the structure of the deposits at $R_{C}=2 \mu \mathrm{m}$ for $P e=0.01-10$, at the time of capillary clogging. Similar to Fig. 2 , clogging takes place mainly outside of the capillary, as approximately $83-60 \%(P e=0.01-10)$ of the particle mass is deposited there at $t_{c l}$. The development of the void cone-like structure revealed in Fig. 2 is also observed in Fig. 5 , where the solid volume is seen to increase at increasing distance from the capillary inlet.

The time required for clogging decreases from 10,000 to 130 s with Pe increasing from 0.01 to 10 . Increasing the Pe from 0.01 to 10 , increases the particle flux by 3 orders of magnitude, however the clogging time only decreases by 2 orders of magnitude. The reason is that the $\phi_{s d}$ increases with increasing Pe allowing more particles to deposit before clogging.

The height of the deposit (Fig. 5b, $h_{c l}$ ) and the shaded area (Fig. 5a) at capillary clogging increases from $3 \mu \mathrm{m}$ and $75 \%$ to $5.7 \mu \mathrm{m}$ and $100 \%$ with increasing Pe from 0.01 to 10 . This is an effect of larger residence time at low Pe numbers, which allows particles to be captured by diffusion within the deposit before penetrating to the capillary-inlet. This means, that fine particles have a better chance of being captured by the filter without penetrating through it. Therefore, the height of the deposit, as well as the narrowing of the capillary inlet rim required for clogging is smaller with decreasing Pe. The void cone-like structure seen for $P e=1$ (cf. Fig. $2 \mathrm{~b}$ ), becomes even more pronounced at $P e=10$ (Fig. $5 \mathrm{c}$ ), as particle motion become even more ballistic and particles just pile on top of each other. At $P e=10$, the tip of the void cone and clogging height $\left(h_{c l}\right)$ coincides well with that estimated from Eq. (12) $\left(\delta_{c l}=4 \mu \mathrm{m}\right)$.

Fig. 6 shows the $\phi_{s d}$ profiles for deposits grown at $P e=10$ to a height $\delta_{\text {cake }}=9 \mu \mathrm{m}$ for capillary radii $R_{c}=1,2$ and $4 \mu \mathrm{m}$. As for $P e=0.01$ and 1 (cf. Fig. 3), a constant solid volume fraction $\left(\phi_{s d, c}\right)$ is obtained here for $R_{c}=1$ and $2 \mu \mathrm{m}$. From Fig. 6 the height above the capillary-inlet at which $\phi_{s d, c}$ is obtained is $6 \mu \mathrm{m}$ for $R_{c}=2 \mu \mathrm{m}$, which is in agreement with $h_{c l}=5.7 \mu \mathrm{m}$ for $P e=10$ on Fig. 5. Therefore, as expected from Fig. 3, $\phi_{s d, c}$ is reached only if the capillary is clogged, so at $P e=10$ and $R_{c}=4 \mu \mathrm{m}$, the capillary is not yet clogged.

Fig. 7 compares the constant solid volume fraction $\left(\phi_{s d, c}\right)$ as function of Pe obtained here (solid line, triangles) to that for deposition on a flat surface (broken line, circles) by Rodríguez-Pérez et al. (2005). Also shown is the clogging time, $t_{c l}$, (solid line, squares) for filtration of $d_{p}=50 \mathrm{~nm}$ particles with $C_{n}=10^{14} \mathrm{\#} / \mathrm{m}^{3}$ through a capillary of $R_{c}=2 \mu \mathrm{m}$.

Similar trends for the two different geometries are seen. This is not surprising, as once the capillary is clogged, the effect of its walls becomes negligible and deposition continues, as it would occur on a flat surface. Differences arise from different integration method as Rodríguez-Pérez et al. (2005) used a grid, where particles were restricted to move only by jumping from grid point to grid point, while here a continuous model is used allowing for a less restricted particle motion. Fig. 7 shows also, that the ballistic limit (dotted line, $\phi_{s d, c}=0.15$ ) obtained both experimentally and numerically by Blum and Schräpler (2004) is approached here at $P e=10$. Following Rodríguez-Pérez et al. (2005), regression through $\phi_{s d, c}$ (solid line, triangles) gives:

$$
\phi_{s d, c}=0.15\left(1+\frac{1.5}{P e}\right)^{-0.5}
$$

This shows that $\phi_{s d, c}$ is a function of Pe alone for constant flow filtration of monodisperse nanoparticles. As it will be shown in Section 3.3, this along with the clogging time (solid line, squares) allow for the use of filtration theory to predict the pressuredrop evolution. 


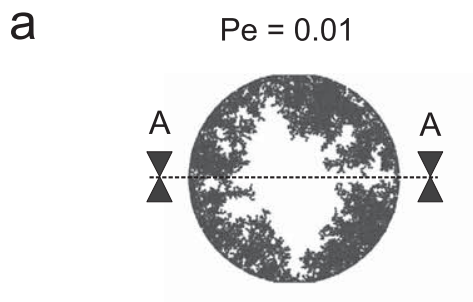

b
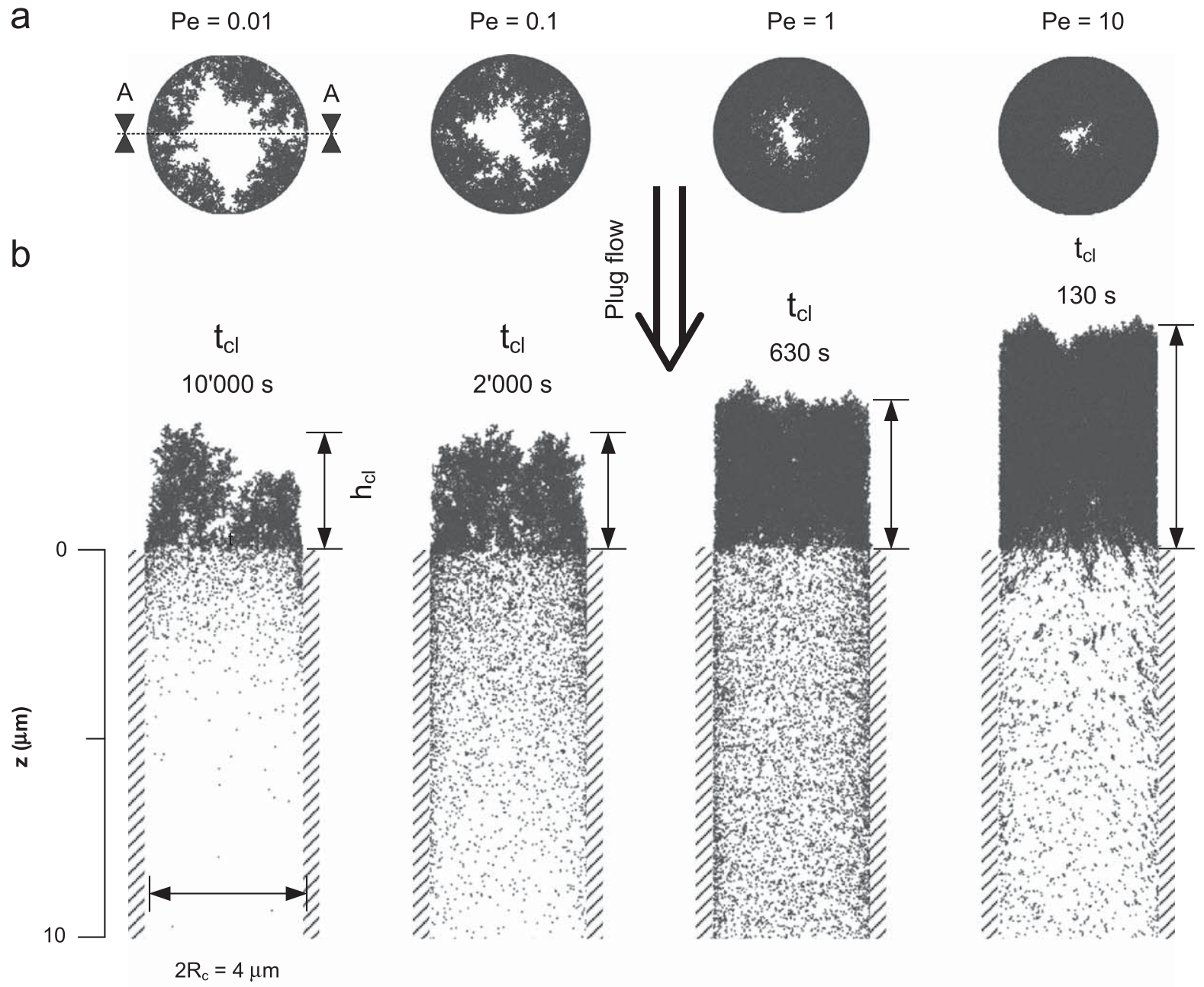

C
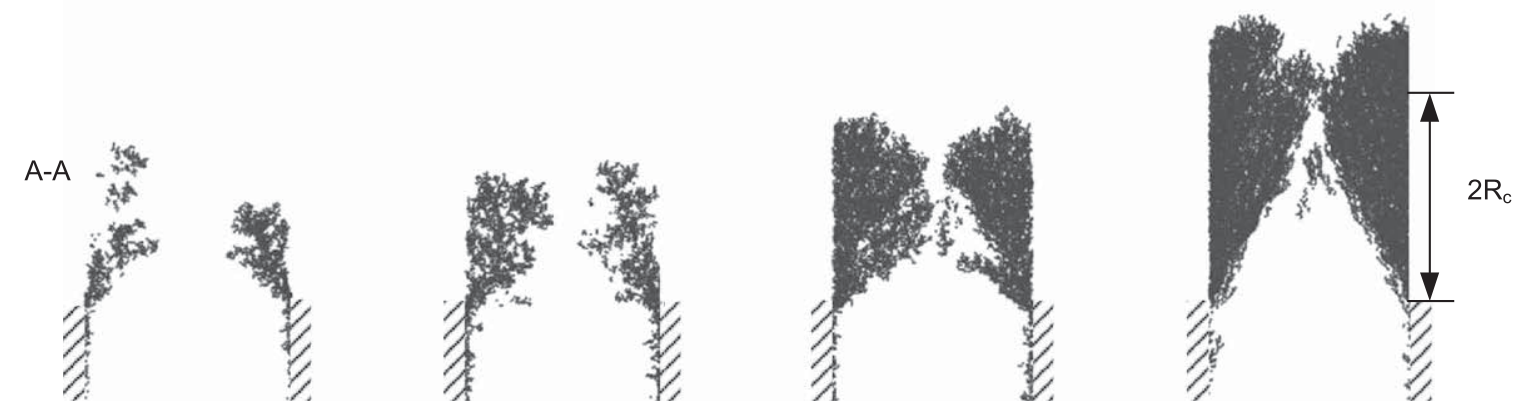

Fig. 5. Structure of deposits formed by filtration of $50 \mathrm{~nm}$ particles at the time of capillary clogging for $P e=0.01-10$. With increasing Pe, the shading effect increases (a). For $P e=0.01$, the shaded area is $75 \%$, while at $P e=10$ this is nearly $100 \%$. The clogging height $\left(h_{c l}\right)$ and solid volume fraction increase with increasing Pe (b). Cross-sectional cuts reveal that particle deposition takes place mainly outside of the capillary (c). The shape of the deposit at $P e \geq 1$ resembles that of a void cone.

\subsection{Filtration dynamics}

Fig. 8 shows the evolution of filtration efficiency, $\eta$, (solid lines) as well as the overall fraction of penetrated mass, $\bar{P}$, (broken lines) for $50 \mathrm{~nm}$ particles and a $10 \mu \mathrm{m}$ long capillary with $R_{c}=2 \mu \mathrm{m}$ at $P e=1$ (bold lines) and $P e=10$ (thin lines). For $P e=0.01-0.1$, the filtration efficiency was at all times $>99 \%$. As expected (Japuntich et al., 1994), the filtration efficiency increases with time as the capillary progressively clogs and shades off incoming particles. The initial filtration efficiency is lowest, as not all particles have sufficient residence time within the $10 \mu \mathrm{m}$ long capillary to deposit by diffusion (Gormley \& Kennedy, 1949). As the flow-rate increases proportionally to $P e$, this effect naturally increases with increasing $P e$. For $P e=1$, 


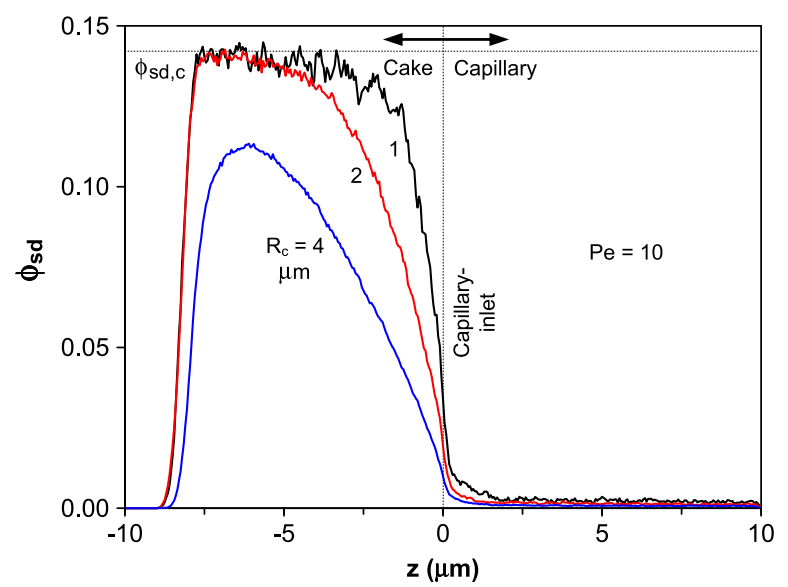

Fig. 6. Solid volume fraction $\left(\phi_{s d}\right)$ profile through cake and capillary for $P e=10$ and cake growth of up to $9 \mu$ m. The maximum (and constant) $\phi_{s d, c}$ is reached in the cake for $R_{c}=1$ and $2 \mu \mathrm{m}$. For $R_{c}=4 \mu \mathrm{m}$, this is not the case as the cake is still developing and the capillary is not yet clogged.

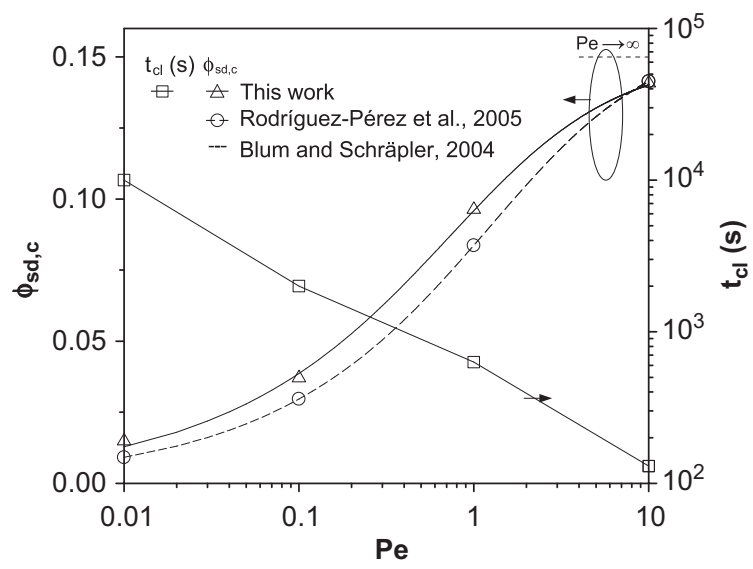

Fig. 7. Constant solid volume fraction $\left(\phi_{s d, c}\right)$ and clogging time $\left(t_{c l}\right)$ as a function of the Pe number for filtration of $d_{p}=50 \mathrm{~nm}$ particles, with $C_{n}=10^{14} \# / \mathrm{m}^{3}$ in a $R_{c}=2 \mu \mathrm{m}$ capillary by this work (solid lines) and comparison to Rodríguez-Peréz et al. (2005) for flat surface deposition (broken line). The constant solid volume fraction increases with increasing Pe, which is in good agreement with the compact structure obtained at high Pe by Blum and Schräpler (2004) (dotted line). The solid line between the points of $\phi_{s d, c}$ (triangles) has been calculated using the interpolation formula (Eq. (27)).

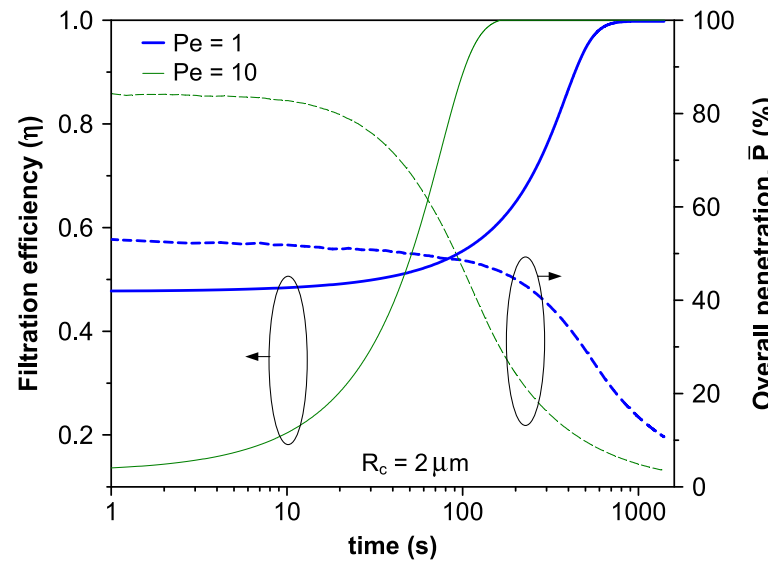

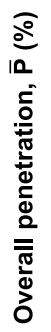

Fig. 8. Evolution of the filtration efficiency $(\eta)$ (solid lines) and the overall penetration $(P)$ (dashed lines) for $P e=1$ (bold lines) and 10 (thin lines). For both $P e$, the filtration efficiency increases with time, as the filter becomes progressively clogged. The present LD simulations are in agreement with the perfect sink model (Gormley \& Kennedy, 1949) using plug-flow regarding the initial filtration efficiency $(t<10$ s for both $P e$ ) at the capillary outlet. 


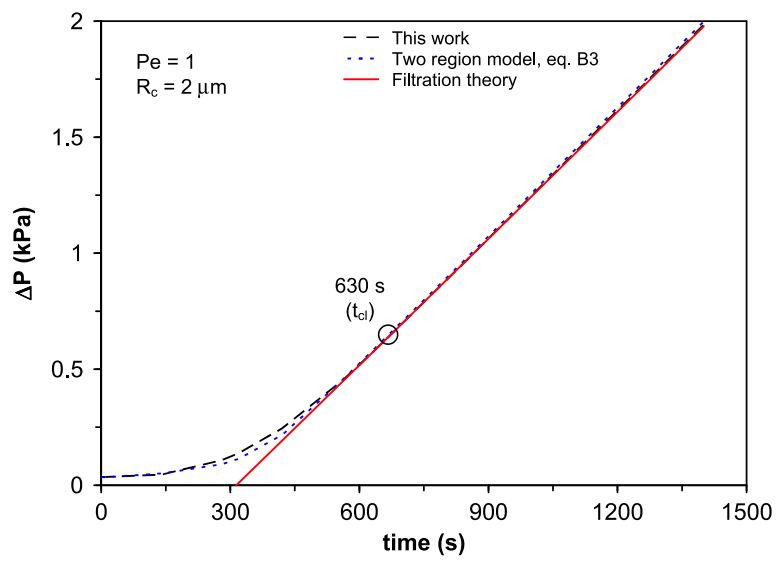

Fig. 9. Evolution of pressure-drop from the average permeability (dashed line, Eqs. (16) and (18)) and the two-region (dotted line, Eq. (B.3)) models at $P e=1$ for a $10 \mu \mathrm{m}$ long capillary of $2 \mu \mathrm{m}$ radius and comparison to classic filtration theory for cake filtration (solid line, Eq. (25)) at constant solid volume fraction $\left(\phi_{s d, c}=0.1\right)$. The initial slow increase of $\Delta P$ (dashed line) is attributed to the effect of capillary clogging. After $t_{c l}(630 \mathrm{~s})$ and regardless of model, the cake builds up at constant $\phi_{s d}$ and the pressure-drop evolution becomes constant according to filtration theory for incompressible gasses.

approximately $48 \%$ of the particles are collected initially, while for $P e=10$, only around $18 \%$ are. Both values are in agreement with the perfect sink model (Gormley \& Kennedy, 1949) using plug-flow. The overall penetration, $\bar{P}$, at the time of clogging therefore also increases with increasing $P e$ from $\bar{P}=23 \%$ at $P e=1$ to $\bar{P}=37 \%$ at $P e=10$.

Fig. 9 shows the pressure-drop evolution at $P e=1$ with $R_{c}=2 \mu \mathrm{m}$, with the clogging time $\left(t_{c l}=630 \mathrm{~s}\right)$ displayed to show the change into cake filtration. The pressure-drop (dashed line) has been calculated from Eqs. (16) and (18). The curve shape agrees with well those obtained experimentally by Stenhouse and Trottier (1991) and Thomas et al. (2001), as well as numerically by Schmidt (1996). During capillary deposition ( $<10 \mathrm{~s}$, cf. Fig. 4 ), the pressure-drop is low and its increase is slow so capillary deposition does not contribute significantly to the pressure-drop evolution. The pressure-drop starts increasing more rapidly when particles deposit inside $(t>0)$ and, in particular, outside $(t>10 \mathrm{~s})$ of the capillary until its clogging $(t \leq 630 \mathrm{~s})$ that marks the onset of cake filtration when pressure-drop steeply increases.

The shape of the pressure-drop curve is compared to the one obtained from filtration theory (Eq. (25), Fig. 9 solid line) at $\phi_{s d, c}=0.1$ (Fig. 7, $P e=1$ ). After the capillary has been clogged ( $630 \mathrm{~s}$ ), the pressure-drop evolution predicted by the present LD model asymptotically approaches the classic filtration theory. This is attributed to cake growth with constant solid volume fraction (Fig. 3). Before clogging, however, filtration theory does not predict the pressure-drop evolution (Fig. 9, solid line).

The present model is based on an average permeability throughout each axial position $(z)$ of the growing deposit. As shown in Fig. 2, the deposit that grows before cake formation consists of a particle-free and a particle-laden region. An alternative model for the calculation of the pressure-drop evolution based on these two regions is presented in Appendix B. Little difference, however, is observed between this two-region model (blue dotted line, Fig. 9, Eq. (B.3)) and the average permeability model (black dashed line, Fig. 9, Eqs. (16) and (18)). Given the extra complexity of judiciously splitting the flow through the two regions (e.g. selection of $R_{o}$ in Fig. B1b), the average permeability model is preferred here.

Fig. 10 shows the evolution of the pressure-drop scaled with the fluid velocity $U$ for $P e=0.01-10$ with $R_{c}=2 \mu \mathrm{m}$ as a function of the deposited mass. For $P e=10$ the pressure-drop becomes non-linear with the deposited mass. This is not a unique feature at $P e=10$, but arises from a combination of a high cake solid volume fraction $\left(\phi_{s d, c}=0.14\right)$ and small particles $(50 \mathrm{~nm})$, which makes a cake of low permeability (cf. Eq. (21)). Together with a high filtration flow-rate, the gas becomes compressed resulting in a non-linear response in the pressure build-up. In comparison, at lower Pe numbers (0.01-1), the pressure-drop approaches an asymptotic linear slope, which is expected in cake filtration for incompressible gases, however the pressure-drop curves do not collapse into one. The reason for this is the changing solid volume fraction with changing Pe. In fact, the permeability $B_{0, c}$ (Eq. (22)) through the cake decreases by two orders of magnitude when the cake solid volume fraction $\left(\phi_{s d, c}\right)$ increases from 0.015 to 0.14 with increasing Pe from 0.01 to 10 (Fig. 7 ). The largest increase in pressure-drop takes place during growth of the filter cake, which is the part that can be estimated by classic filtration theory. Therefore, the accurate determination of the clogging time and the cake solid volume fraction, obtained here, are essential in predicting the pressure-drop evolution by classic filtration theory.

\subsection{Comparison with simplified void-cone clogging model}

The expression for $\phi_{s d, c}$ as a function of Pe (Eq. (27)) was used together with Eq. (8) to calculate $t_{c l}$. Fig. 11 compares these values to the ones obtained by Langevin dynamics for three $R_{c} / d_{p}=20-80$ (corresponding to $R_{c}=1-4 \mu \mathrm{m}$ for $d_{p}=50 \mathrm{~nm}$ ) and $P e=0.01-10$. Excellent agreement was found between the two calculations indicating the effectiveness of Eq. (8). A small 


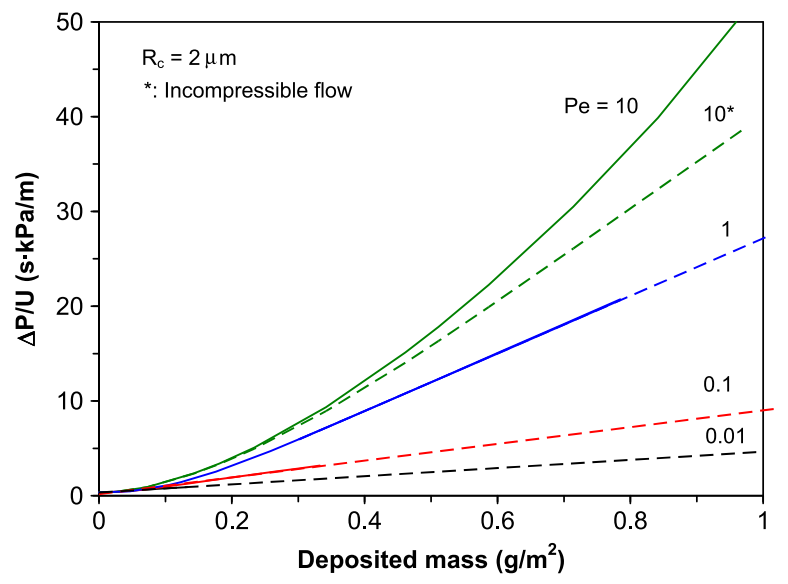

Fig. 10. Pressure-drop $\Delta P$ normalized by the flow velocity $U$ as a function of deposited mass. As little particle mass is deposited at $P e=0.01-1$ for $\delta_{\text {cake }}=9 \mu \mathrm{m}$, these $\Delta P$ have been extrapolated using classic filtration theory, Eq. (23) (broken lines). At $P e=10$ (solid line), clear deviation from the incompressible gas filtration theory (Eq. (24)) (10*, dashed line) is observed. At $P e<10$ the gas can be considered incompressible, as both lines calculated from Eqs. (23) and (24) collapse on each other. The increase in cake solid volume fraction $\phi_{s d, c}$ from $P e=0.01$ to $P e=10$ decreases the cake permeability increasing the pressure-drop.

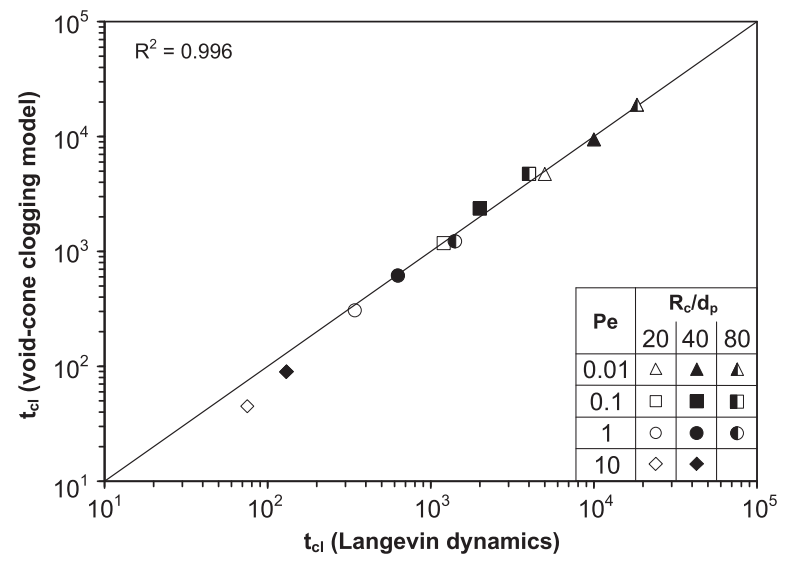

Fig. 11. Comparison between the time for capillary clogging, $t_{c l}$, (symbols) calculated from Eq. (8) and from Langevin dynamics for $R_{c} / d_{p}=20-80$ (capillary radius $R_{c}=1-4 \mu \mathrm{m}$ for particle diameter $d_{p}=50 \mathrm{~nm}$ ) and $P e=0.01-10$. Excellent agreement is observed between the two calculations (coefficient of determination $R^{2}=0.996$ ).

deviation at $P e=10$ is observed as $t_{c l}$ is shortest there that leads to an increasing relative error from particle statistics. Therefore, Eq. (8) together with Eq. (27) may be used to estimate a priori the time of clogging, $t_{c l}$.

\section{Conclusions}

The detailed three-dimensional morphology and time-evolution of deposit structure during nanoparticle filtration through a capillary in highly porous filters was obtained by Langevin dynamics (LD) as a function of Pe number (0.01-10). The transition between capillary and cake filtration was elucidated by allowing particle deposits to grow continuously. Three distinct time-regimes were observed. In the first regime (capillary deposition), deposition occurred inside the capillary. In the second regime (capillary clogging), deposition occurred both inside and outside of the capillary, gradually clogging the capillary-inlet by interception of incoming particles. In the last regime (cake growth), the capillary was fully clogged as no particle penetration occurred through the capillary-inlet and depositing particles formed a cake with constant solid volume fraction $\left(\phi_{s d, c}\right)$.

Clogging took place mostly outside of the capillary as $83-60 \%(P e=0.01-10)$ of the total particle mass had been deposited there at the time of capillary clogging $\left(t_{c l}\right)$ for a capillary radius and length of 2 and $10 \mu \mathrm{m}$ respectively. The $t_{c l}$ marked the onset of cake growth, as determined by monitoring the particle flux through the capillary-inlet for various Pe numbers. The $t_{c l}$ decreased from 10,000 to $130 \mathrm{~s}$ with Pe increasing from 0.01 to 10 . The $t_{c l}$ did not linearly decrease with increasing flux, as the higher $P e$ increased the solid volume fraction of the cake. 
At low Pe numbers, particles deposited primarily by diffusion resulting in fractal-like structures with a low cake solid volume fraction $\left(\phi_{s d, c}=0.015\right.$ at $\left.P e=0.01\right)$ consistent with experimental studies (Mädler, \& Roessler et al., 2006). At high Pe, the cake structure was more compact by ballistic deposition $\left(\phi_{s d, c}=0.14\right.$ at $\left.P e=10\right)$. The clogging height increased from 3 to $5.7 \mu \mathrm{m}$ with $P e$ increasing from 0.01 to 10 . At higher Pe, a void cone was formed with its tip corresponding to the clogging height and nearly equal to that of capillary diameter.

The evolution of pressure-drop and filtration efficiency time-evolution for constant flow filtration was investigated for $P e=0.01-10$ and was consistent with experimental data. Initially the pressure-drop and filtration efficiency was low and the increase was slow as particles mainly deposited inside the capillary. As the capillary-inlet became progressively shielded by intercepted particles both started increasing more rapidly. Therefore, the pressure-drop rise by capillary deposition was negligible for all Pe numbers. After capillary clogging, the pressure-drop evolution asymptotically reached the classical theory for cake filtration with constant solid volume fraction $\left(\phi_{s d, c}\right)$ and perfect filtration efficiency (equal to 1). While at $P e=0.01-0.1$, where at all times every particle was collected before penetrating the $2 \mu \mathrm{m}$ radius and $10 \mu \mathrm{m}$ long capillary, a significant amount of the total filtered particles at $t_{c l}(23-37 \%)$ had penetrated the capillary at $P e=1-10$.

The cake permeability was decreased by two orders of magnitude with increasing Pe from 0.01 to 10 . This increased the pressure-drop above what was expected by mainly increasing the flow. Based on the deposit structure, an analytical expression was derived linking the capillary clogging time, $t_{c}$, with filtration process parameters, as well as cake solid volume fraction, $\phi_{s d, c}$. Excellent agreement was observed between the analytical and LD simulations for the clogging time over the entire range of Pe numbers studied here. Furthermore, an expression giving the height of the void-cone, $\delta_{c l}$, was also derived, showing that it is in the order of one capillary diameter for large Pe. As a significant part of the pressure-drop increase occurred during cake growth, the clogging time and the asymptotic cake solid volume fraction determined here by LD and analytical expressions are two important parameters for design and operation of filtration units.

\section{Acknowledgments}

We thank ETH Zürich for the use of the Gonzales cluster in the simulations and financial support by The Danish Council of Technological Research, Nanoprim (contract number: NMP3-CT-2007-033310) and CCMX-Nancer.

\section{Appendix A. Pressure-drop of compressible gas through a clogged capillary}

After clogging, a cake with constant solid volume fraction, $\phi_{s d, c}$, builds up on top of the capillary clog as indicated on Fig. A1. The total pressure-drop can be found by adding the pressure-drop of the clog to the pressure-drop of the cake.

$$
\Delta P=\Delta P_{c l}(t)+\Delta P_{\text {cake }}(t)
$$

where $\Delta P_{c l}(t)$ is the pressure-drop across the clog at $t>t_{c l}$ and it is equal to:

$$
\Delta P_{c l}(t)=P_{i}(t)-P_{c, o}(t)
$$

This pressure-drop is calculated in two parts: (a) through the clog outside of the capillary by Darcy's law (Eq. (18)), and (b) inside the capillary by the modified Poiseuille's law (Eq. (16)). Summation of the two pressure-drops eliminates the unknown $P_{c, i}$ at $z_{c, i}$ (capillary inlet):

Darcy's law for the clog outside of the capillary is:

$$
\frac{1}{2}\left(P_{i}^{2}-P_{c, i}^{2}\right)=\frac{Q_{0} P_{0} \mu}{\pi R_{c}^{2}} \int_{z_{c, i}}^{z_{i}(t)} \frac{d z}{B_{0}(t, z)}=k_{1}
$$

where $z_{i}$ is the height of the clog. After clogging $\left(t>t_{c l}\right), z_{i}$ and $B_{0}(z)$ become constant and for constant flow filtration the entire right-hand side (RHS) $\left(k_{1}\right)$ of Eq. (A.3) also becomes constant in time. This is because particles generally do not penetrate deeply through the deposit below the cake and thereby they do not decrease $B_{0}(z)$ or increase $z_{i}$.

Similarly, the pressure-drop through the capillary section (modeled by Poiseuille's law) is:

$$
\frac{1}{2}\left(P_{c, i}^{2}-P_{c, 0}^{2}\right)=\frac{8 Q_{0} \mu P_{0}}{\pi R_{c}^{4}} \int_{z_{c, o}}^{z_{c, i}} \frac{d z}{\left(1-\phi_{s d}(z)\right)^{2}}=k_{2}
$$

where $k_{2}$ is also constant after $t_{c l}$. Adding Eqs. (A.3) and (A.4) yields the total pressure-drop:

$$
\frac{1}{2}\left(P_{i}^{2}-P_{c, 0}^{2}\right)=k_{1}+k_{2}
$$

Therefore $\left(P_{i}^{2}-P_{c, o}^{2}\right)$ is equal to a constant after clogging $\left(t>t_{c l}\right)$, however $P_{i}-P_{c, o}$ is not. The $2\left(k_{1}+k_{2}\right)$ is determined as follows: at $t_{c l}$, the interface pressure $P_{i}=P_{0}$ since no cake has yet formed. Then the total pressure-drop across the filter is $\Delta P\left(t_{c l}\right)=P_{0}-P_{c, o}\left(t_{c l}\right)$ and inserting into Eq. (A.5) gives:

$$
P_{0}^{2}-P_{c, o}^{2}\left(t_{c l}\right)=P_{0}^{2}-\underbrace{\left(P_{0}-\Delta P\left(t_{c l}\right)\right)^{2}}_{P_{c, 0}^{2}\left(t_{c l}\right)}=2\left(k_{1}+k_{2}\right)
$$




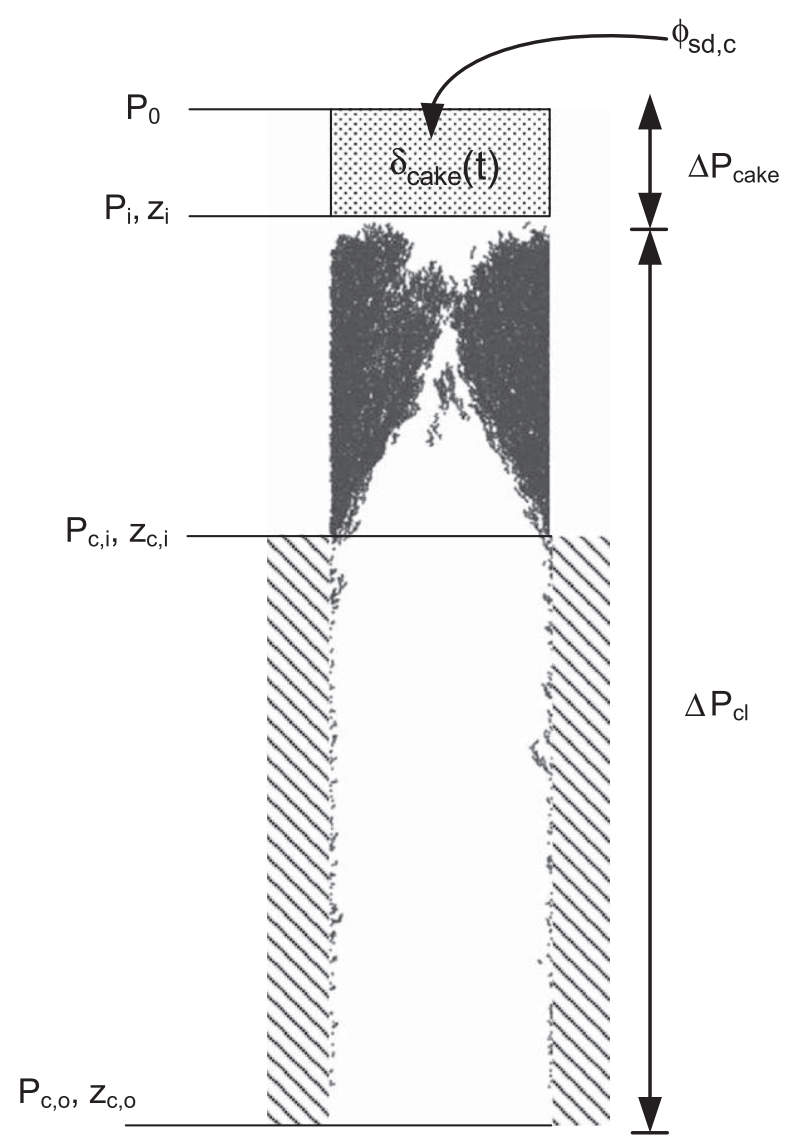

Fig. A1. Cake filtration on top of a clogged capillary. The pressure at the filter inlet is $P_{0}=1 \mathrm{~atm}$ and the pressure at the capillary outlet $\left(P_{c, 0}\right)$ is determined by the structure of the deposit formed during filtration.

This gives $\kappa$ as (Eq. (26)):

$$
\kappa=k_{1}+k_{2}=\frac{1}{2}\left(P_{0}^{2}-\left(P_{0}-\Delta P\left(t_{c l}\right)\right)^{2}\right)
$$

We see that at $t>t_{c l}$ the pressure-drop across the clog is:

$$
\Delta P_{c l}(t)=\underbrace{P_{i}}_{P_{0}-\Delta P_{\text {cake }}}-\overbrace{P_{c, 0}}^{\sqrt{P_{i}^{2}-2 \kappa}}=\underbrace{P_{0}-\Delta P_{\text {cake }}}_{P_{i}}-\overbrace{{\sqrt{\left(P_{0}-\Delta P_{\text {cake }}\right)^{2}-2 \kappa}}^{P_{c, o}}}^{\underbrace{}}
$$

which is a function of $\Delta P_{\text {cake }}$ that is an increasing function of time and therefore the pressure-drop across the clog is as well a function of time. Finally, the total pressure-drop can be found by adding $\Delta P_{c l}(t)$ and $\Delta P_{\text {cake }}(t)$ :

$$
\Delta P=\Delta P_{c l}(t)+\Delta P_{\text {cake }}(t)=P_{0}-\sqrt{\left(P_{0}-\Delta P_{\text {cake }}\right)^{2}-2 \kappa}
$$

\section{Appendix B. Two region model for pressure-drop across a particle-laden capillary}

From the snapshots in time during particle filtration (Fig. 2a), one can clearly observe a particle-free region, as well as a region where particle deposits are concentrated (at higher $P$ e, this is observed as the formation of a void-cone). Fig. B1 shows how the particle-free region is described by a circle with an equivalent radius $R_{o}$, while the particle-laden region is located in the annulus between $R_{c}$ and $R_{o}$. In each axial slice, the particle-free region, $R_{o}$, is selected by locating the minimum distance between the center-axis and a deposited particle in that slice (Fig. B1). This assumption becomes increasingly better at higher $P e$, where the distinction between the two regions becomes more pronounced. In the following, it is assumed that the pressure-drop through the particle-laden region can be calculated by Darcy's law (Eq. (18)) and through the particle-free region by Poiseuille's law (Eq. (16)). The calculated pressure-drop gradient in a given slice at 


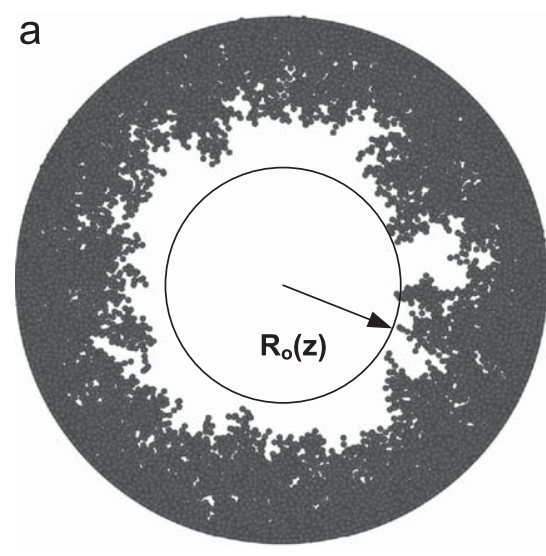

LD model

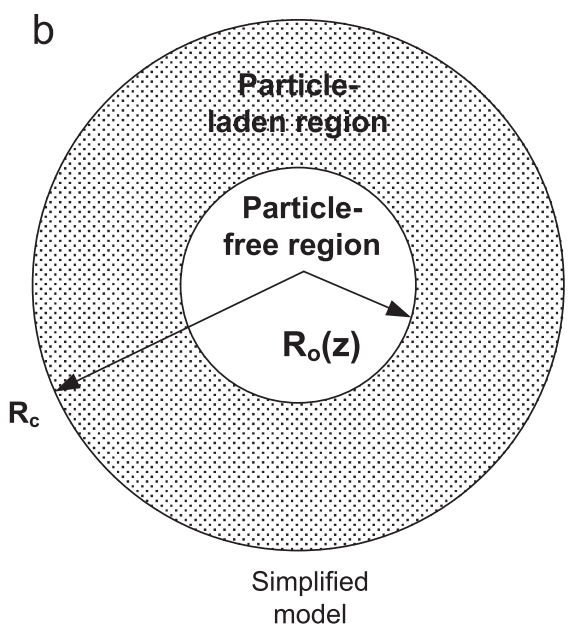

Fig. B1. Snapshots of particle deposits through a capillary slice before clogging ( $P e=1, t=320 \mathrm{~s}$ ) by the LD model (a) and an equivalent schematic of a simplified model (b) showing a particle-free region, characterized by a circle with radius $R_{o}$ and a particle-laden region where all particles are deposited in the annulus between $R_{c}$ and $R_{o}$.

any axial position " $z$ " in each radial region is in equilibrium and therefore:

$$
\frac{d P}{d z}=\underbrace{-\frac{\dot{n}_{d} R T}{P} \frac{\mu}{B_{0}(t, z) \pi\left(R_{c}^{2}-R_{0}^{2}\right)}}_{\mathrm{dp} / \mathrm{dz} \text { in particle-laden }}=\underbrace{-\frac{\dot{n}_{0} R T}{P} \frac{8 \mu}{\pi R_{0}^{4}}}_{\mathrm{dp} / \mathrm{dz} \text { in particle-free region }}
$$

where $\dot{n}_{d}$ and $\dot{n}_{o}$ are the molar fluxes through the particle-laden and free regions, respectively. These may be expressed through the total molar flux obtained from the total flow $Q_{0}$ at $P=P_{0}$ :

$$
Q_{0}=\left(\dot{n}_{d}+\dot{n}_{o}\right) \frac{P_{0}}{R T}
$$

Inserting Eqs. (B.2) into (B.1) and integrating over deposit length, including the capillary itself:

$$
\Delta P(t)=P_{0}-\sqrt{P_{0}^{2}-\frac{16 Q_{0} \mu}{\pi} \int_{\delta} \frac{1}{8 \pi\left(R_{c}^{2}-R_{o}^{2}(t, z)\right) B_{0}(t, z)+R_{o}^{4}} d z}
$$

Eq. (B.3) reduces to Poiseuille's law when $R_{o}=R_{c}$, and to Darcy's law when $R_{o}=0$.

\section{References}

Andersen, S. K., Johannessen, T., Mosleh, M., Wedel, S., Tranto, J., \& Livbjerg, H. (2002). The formation of porous membranes by filtration of aerosol nanoparticles. Journal of Nanoparticle Research, 4(5), 405-416.

Bird, R. B., Stewart, W. E., \& Lightfoot, E. N. (2002). Transport phenomena ((2nd ed.)). New York: Wiley.

Blum, J., \& Schräpler, R. (2004). Structure and mechanical properties of high-porosity macroscopic agglomerates formed by random ballistic deposition Physical Review Letters, 93(11), 115503-1-115503-4.

Calle, S., Contal, P., Thomas, D., Bemer, D., \& Leclerc, D. (2002a). Evolutions of efficiency and pressure drop of filter media during clogging and cleaning cycles. Powder Technology, 128(2-3), 213-217.

Calle, S., Contal, P., Thomas, D., Bemer, D., \& Leclerc, D. (2002b). Description of the clogging and cleaning cycles of filter media. Powder Technology, 123(1), 40-52.

Chakraborty, D., Bischoff, H., Chorkendorff, I., \& Johannessen, T. (2005). Mixed phase Pt-Ru catalyst for direct methanol fuel cell anode by flame aerosol synthesis. Journal of Electrochemical Society, 152(12), A2357-A2363.

Davies, C. N. (1970). Clogging of fibrous aerosol filters. Journal of Aerosol Science, 1, 35-39.

Elias-Kohav, T., Sheintuch, M., \& Avnir, D. (1991). Steady-state diffusion and reactions in catalytic fractal porous-media. Chemical Engineering Science, $46(11), 2787-2798$.

Ergun, S., \& Orning, A. A. (1949). Fluid flow through randomly packed columns and fluidized beds. Industrial \& Engineering Chemistry, 41, 1179-1184.

Ermak, D. L., \& Buckholz, H. (1980). Numerical-integration of the Langevin equation-Monte-Carlo simulation. Journal of Computational Physics, 35(2) $169-182$.

Fan, K. C., \& Gentry, J. W. (1978). Clogging in nuclepore filters. Environmental Science \& Technology, 12(12), 1289-1294.

Friedlander, S. K. (2000). Smoke, dust, and haze: Fundamentals of aerosol dynamics (2nd ed). New York: Oxford University Press.

Gormley, P. G., \& Kennedy, M. (1949). Diffusion from a stream flowing through a cylindrical tube. Proceedings of the Royal Irish Academy, 163-169.

Heine, M. C., \& Pratsinis, S. E. (2007). Brownian coagulation at high concentration. Langmuir, 23(19), 9882-9890.

Hinds, W. C., \& Kadrichu, N. P. (1997). The effect of dust loading on penetration and resistance of glass fiber filters. Aerosol Science and Technology, 27(2), $162-173$.

Jackson, R. (1977). Transport in porous catalysts. New York: Elsevier Scientific Publishing Co. 
Japuntich, D. A., Stenhouse, J. I. T., \& Liu, B. Y. H. (1994). Experimental results of solid monodisperse particle clogging of fibrous filters. Journal of Aerosol Science, 25(2), 385-393.

Johannessen, T., Jensen, J. R., Mosleh, M., Johansen, J., Quaade, U., \& Livbjerg, H. (2004). Flame synthesis of nanoparticles—applications in catalysis and product/process engineering. Chemical Engineering Research \& Design, 82(A11), 1444-1452.

Kirsch, V. A. (1998). Method for the calculation of an increase in the pressure drop in an aerosol filter on clogging with solid particles. Colloid Journal, 60(4), 439-443.

Lundgren, T. S. (1972). Slow flow through stationary random beds and suspensions of spheres. Journal of Fluid Mechanics, 51, 273-299.

Mädler, L., Lall, A. A., \& Friedlander, S. K. (2006). One-step aerosol synthesis of nanoparticle agglomerate films: Simulation of film porosity and thickness. Nanotechnology, 17(19), 4783-4795.

Mädler, L., Roessler, A., Pratsinis, S. E., Sahm, T., Gurlo, A. Barsan, N. et al. (2006). Direct formation of highly porous gas sensing films by in situ thermophoretic deposition of flame-made Pt/SnO 2 nanoparticles. Sensors and Actuators B-Chemical, 114(1), 283-295.

Manton, M. J. (1978). Impaction of aerosols on a nuclepore filter. Atmospheric Environment, 12(8), 1669-1675.

Nakayama, A., Kuwahara, F., \& Sano, Y. (2007). Concept of equivalent diameter for heat and fluid flow in porous media. AIChE Journal, 53(3), 732-736.

Nield, D. A., \& Bejan, A. (2006). Convection in porous media ((3rd ed.)). New York: Springer.

Novick, V. J., Monson, P. R., \& Ellison, P. E. (1992). The effect of solid particle mass loading on the pressure-drop of hepa filters. Journal of Aerosol Science, 23(6), 657-665.

Pawu, K. T., \& Braaten, D. A. (1995). New perspectives on rebound and reentrainment processes. Aerosol Science and Technology, 23(1), 72-79.

Podgorski, A. (2009). Estimation of the upper limit of aerosol nanoparticles penetration through inhomogeneous fibrous filters. Journal of Nanoparticle Research, 11(1), 197-207.

Przekop, R., Moskal, A., \& Gradon, L. (2003). Lattice-Boltzmann approach for description of the structure of deposited particulate matter in fibrous filters. Journal of Aerosol Science, 34(2), 133-147.

Reis, F. D. A. A. (2005). Statistical models of diffusion and aggregation for coke formation in a catalyst pore. Physica A-Statistical Mechanics and Its Applications, 350(2-4), 407-417.

Rodríguez-Pérez, D., Castillo, J. L., \& Antoranz, J. C. (2005). Relationship between particle deposit characteristics and the mechanism of particle arrival. Physical Review E, 72(2), 021403-1-021403-9.

Russ, B. E., \& Talbot, J. (1998). A method for measuring the adhesion strength of powder coatings. The Journal of Adhesion, 68(3-4), 257-268.

Ruth, B. F. (1935). Studies in filtration III. Derivation general filtration equations. Industrial and Engineering Chemistry, 27, 708-723.

Schmidt, E. (1996). Simulation of three-dimensional dust structures via particle trajectory calculations for cake-forming filtration. Powder Technology, $86(1), 113-117$.

Smith, T. N., \& Phillips, C. R. (1975). Inertial collection of aerosol-particles at circular aperture. Environmental Science E Technology, 9(6), 564-568.

Song, C. B., Park, H. S., \& Lee, K. W. (2006). Experimental study of filter clogging with monodisperse PSL particles. Powder Technology, 163(3), 152-159.

Spurny, K. R., Lodge, J. P., Frank, E. R., \& Sheesley, D. C. (1969). Aerosol filtration by means of nuclepore filters structural and filtration properties. Environmental Science E Technology, 3(5), 453-464.

Stenhouse, J. I. T., \& Trottier, R. (1991). The loading of fibrous filters with submicron particles. Journal of Aerosol Science, 22, S777-S780.

Szekely, J., Evans, J. W., \& Sohn, H. Y. (1976). Gas-solid reactions. New York: Academic Press.

Tassopoulos, M., Obrien, J. A., \& Rosner, D. E. (1989). Simulation of microstructure mechanism relationships in particle deposition. AIChE Journal, 35(6), 967-980.

Thomas, D., Penicot, P., Contal, P., Leclerc, D., \& Vendel, J. (2001). Clogging of fibrous filters by solid aerosol particles—experimental and modelling study. Chemical Engineering Science, 56(11), 3549-3561.

Thybo, S., Jensen, S., Johansen, J., Johannessen, T., Hansen, O., \& Quaade, U. J. (2004). Flame spray deposition of porous catalysts on surfaces and in microsystems. Journal of Catalysis, 223(2), 271-277.

Tricoli, A., Graf, M., Mayer, F., Kühne, S., Hierlemann, A., \& Pratsinis, S. E. (2008). Micropatterning layers by flame aerosol deposition-annealing. Advanced Materials, 20(16), 3005-3010.

Veerapaneni, S., \& Wiesner, M. R. (1994). Particle deposition on an infinitely permeable surface-dependence of deposit morphology on particle-size. Journal of Colloid and Interface Science, 162(1), 110-122.

Wakeman, R. J., \& Tarleton, E. S. (1999). Filtration: equipment selection, modelling and process simulation ((1st ed.)). Oxford, UK, New York: Elsevier Advanced Technology.

Wang, H. C., \& Kasper, G. (1991). Filtration efficiency of nanometer-size aerosol-particles. Journal of Aerosol Science, 22(1), 31-41.

Wang, J., Chen, D. R., \& Pui, D. Y. H. (2007). Modeling of filtration efficiency of nanoparticles in standard filter media. Journal of Nanoparticle Research, 9(1), $109-115$. 